\title{
Typische Fehler im Vorstellungsgespräch
}

Nachdem in den bisherigen Ausführungen bereits zahlreiche No-Gos für Vorstellungsgespräche genannt wurden, findest du im Folgenden eine Zusammenfassung aller elementaren Dinge, die du in deinem Gespräch aktiv vermeiden solltest:

- Lügen

- Schauspielern

- Überheblichkeit

- Unterwürfigkeit

- Jeglicher Umgang mit dem Smartphone

- Mangelndes Wissen über das Unternehmen und dessen Branche

- Unangemessene Körpersprache

- Unangemessene Kleidung

- Stress oder Hektik vermitteln

- Negativ über ehemalige Vorgesetzte und Kollegen reden

- Keine eigenen Fragen stellen

- Unangemessene eigene Fragen stellen

- Offensichtlich auswendig gelernte Antworten geben

- Verspätung, ohne Bescheid zu sagen

Hinweis Das Unternehmen traut dir den Job definitiv zu, sonst wärst du nicht zu einem Gespräch eingeladen worden. Begegne deinen Gesprächspartnern daher auf Augenhöhe und überzeuge auf der menschlichen Ebene. 